\title{
Cancer Risk Assessment and the Genetic Counseling Process: Using Hereditary Breast and Ovarian Cancer as an Example
}

\author{
Sandra K. Prucka Dawn E. Mcllvried Bruce R. Korf \\ Department of Genetics, University of Alabama at Birmingham, Birmingham, Ala., USA
}

\begin{abstract}
Key Words
Qualitative and quantitative risk assessment · Hereditary cancer $\cdot$ Genetic counseling $\cdot$ Hereditary breast and ovarian cancer syndrome
\end{abstract}

\begin{abstract}
While only a small proportion of cancers can be attributed to a hereditary susceptibility, identifying high-risk individuals plays an essential role in medical management and has a significant impact on the patient as well as their immediate and extended family members. This paper aims at increasing the medical professionals' knowledge of the components of a genetic counseling session, with particular attention toward identifying at-risk individuals and understanding the complexities of the testing process. In addition, tools are provided to assist in identifying these individuals in clinical practice and streamlining the referral process to a cancer genetics center.

Copyright $\odot 2008$ S. Karger AG, Basel
\end{abstract}

\section{Introduction}

Cancer arises as a result of genetic changes or mutations that accumulate over time. These mutations occur in genes that normally function to promote proper cell growth and differentiation, which include both protooncogenes and tumor suppressor genes [1]. The majority of cancer is thought to be sporadic, which refers to cancer that arises from age-related risk factors, i.e. somatic errors in DNA replication and/or various environmental exposures. There are families in which certain types of cancer occur more often than what is expected by chance, although the pattern of cancer observed does not generally fit the characteristic features of hereditary cancer. This is often referred to as familial cancer. For individuals within these families, genetic testing for known hereditary cancer susceptibility genes is typically unrevealing. These cancer cases may therefore represent a clustering of sporadic occurrences, or they may be due to a more complex interaction of low-penetrance susceptibility gene(s) and/or environmental factors. In these cases, close relatives of affected family members are often at an increased risk over the general population to develop specific cancers.

For most types of cancer, it is estimated that approximately $5-10 \%$ are hereditary [2-5]. Hereditary cancer refers to the presence of a mutation within a cancer susceptibility gene that is present in an individual at birth (a germ line mutation). Individuals who carry such a mutation are predisposed to develop certain types of cancer or tumors, tend to develop cancer at a younger age than the general population, and may develop more than one primary tumor. Most hereditary cancer demonstrates autosomal dominant inheritance, which translates to a $50 \%$ chance for mutation carriers to pass on the gene mutation to their offspring. A number of different hereditary cancer syndromes have been described, and each is associated with predisposition to specific types or patterns of cancer, de-

\section{KARGER}

Fax +41613061234

E-Mail karger@karger.ch

www.karger.com
(C) 2008 S. Karger AG, Basel

$1011-7571 / 08 / 0173-0173 \$ 24.50 / 0$

Accessible online at:

www.karger.com/mpp
Bruce Korf, MD, PhD

Kaul 241

530 3rd Ave. So.

Birmingham, AL 35294-0024 (USA)

Tel. +1 205934 4983, Fax +1 205975 6389, E-Mail bkorf@uab.edu 
Table 1. Major features of hereditary cancer

- Earlier age of onset of cancer (usually defined as before the age of 50 for most common types of cancer including breast and colon cancer)

- Synchronous and/or metachronous cancers in an individual

- Rare types of cancer in one or more family members (e.g. male breast cancer, medullary thyroid carcinoma, paraganglioma, adrenal cortical carcinoma)

- Multiple ( $\geq 2$ ) blood-related individuals and/or generations with cancer in a family; apparently autosomal dominant inheritance of cancer

- Clustering of specific cancer types within a family (e.g. breast and ovarian; colon and endometrial; thyroid and pancreatic)

Table 2. Physician's pocket guide to hereditary breast and ovarian cancer

Important questions

- Age at breast cancer diagnosed in the patient and in family members

- Number of individuals affected with breast, ovarian, prostate and pancreatic cancer, and relation to the patient

- Ethnic background

- Males affected with breast cancer

- Females affected with bilateral breast cancer and/or breast and ovarian cancer

When to refer for cancer genetic counseling

- Two or more cases of breast cancer in a first- or second-degree relative, especially if one or more of these was premenopausal (defined as $<50$ years of age)

- Ashkenazi Jewish ancestry when there is a family history of breast and/or ovarian cancer

- Personal or family history of breast and ovarian cancer in the same individual

- Bilateral breast cancer

- Male breast cancer

pending on the particular gene involved. The cancer risks may vary depending on the syndrome, the gene involved, the particular mutation within that gene, the age of the affected individual and sometimes also gender. Table 1 shows the major characteristics of hereditary cancer.

\section{Referring to Genetics}

Referral for cancer genetic risk assessment and genetic counseling should be offered for those individuals with a personal and/or family history suggestive of hereditary or familial cancer. Those from high-risk families may benefit from a thorough discussion about the potential risk for hereditary cancer, their personal risks to develop certain cancers, and different available risk reduction screening and management strategies. Such information can ultimately reduce morbidity and mortality within the family. This process is important to enhance patient understanding of cancer risk so that informed decisions can be made with regard to genetic testing, in addition to making appropriate cancer surveillance recommendations and addressing psychosocial issues.

A number of different risk assessment criteria for hereditary cancer have been proposed, and part of the difficulty in determining when to refer a patient for genetic risk assessment has been due to inconsistency of these criteria [6]. Hereditary cancer syndromes may have a variable presentation secondary to incomplete penetrance (the probability that an individual who carries a gene mutation develops symptoms or manifestations of the associated syndrome) and variable expressivity, and family histories in themselves are often dynamic. Thus, key features of hereditary cancer may or may not be evident when taking a family history, and this can make a pedigree difficult to interpret. There are certain rare cancers in which a single case in the family should prompt referral to genetics. The presence of a family member with a known mutation in a cancer susceptibility gene should also indicate referral to genetics for a discussion of testing options. In addition, if there is a familial aggregation or high-risk clustering of different types of cancer in blood relatives, this should also indicate referral to genetics. Many centers may find it helpful to have referral guidelines readily available in a pocket guide format, with key questions to ask patients to distinguish those who are at risk for hereditary cancer. Included in this review is an example of a pocket physician guide that can be used in practice (table 2).

Referral for genetic counseling may also be helpful for those individuals with a personal/family history of cancer who have high levels of anxiety about developing cancer or about the risk for hereditary cancer, even if the family history is not strongly suggestive of a hereditary cancer syndrome. It should also be understood that genetic testing for hereditary cancer is a personal choice and may be declined by some individuals at high risk, just as some individuals at low risk for hereditary cancer may choose to go forward with testing. Although risk assessment criteria can be helpful in making referral decisions, they do not take into account lifestyle and other epidemiological cancer risk factors. Thus, precise quantitative lifetime risk for the development of specific cancers cannot be given using these guidelines. 


\section{Cancer Risk Assessment}

Cancer risk assessment is a process used to identify and counsel those individuals who are at risk for familial or hereditary cancer. There are many aspects to assessing risk for families attending a cancer genetic counseling session. Risk assessment models are available for some hereditary conditions, but even in these cases it is important for the counselor to also incorporate incidence data, family history information and at times make use of available pathology reports. For the purposes of discussing these aspects of risk assessment within this paper, two terms are chosen to best clarify the types of information that are integral to this process. Qualitative risk assessment is focused on the assessment of risk by analysis of the family history and, when possible, incorporates additional information such as incidence data and pathology reports. Quantitative analysis uses risk assessment models to provide a calculation of a patient's risk to carry a mutation in a cancer susceptibility gene. Since risk models are not available for all hereditary conditions, working knowledge of how to critically analyze a family history of cancer is essential to identify those at increased risk and establish recommendations for testing.

To provide accurate qualitative assessment, a detailed personal medical history is required and should include the current age of the patient, any personal history of benign or malignant tumors, major illnesses and hospitalizations, surgical and biopsy history, reproductive history, and cancer surveillance behaviors. If there is a personal history of cancer, the location, pathology, stage and grade of the tumor, the number of primary tumors and treatment information should be obtained, as well as age of diagnosis. When possible, this information should be obtained from pathology reports; however, since this is not always a possibility, obtaining this information from other medical records can be pursued. Family history is also essential to provide informative qualitative assessment and should therefore include at least a 3 -generation pedigree involving both affected and unaffected individuals on maternal and paternal sides of the family. The reference for instructions on constructing a pedigree using standardized nomenclature can be found in table 3 . For those family members with cancer, the current age or age of death, age of diagnosis, type of cancer, number of primary tumors and treatment information are obtained. When possible, cancer diagnoses are confirmed with medical records. Any exposures that might increase the likelihood of cancer development are noted. Since ethnicity can influence the risk for hereditary cancer, it is
Table 3. Resource guide

American Society of Clinical Oncology policy statement update: genetic testing for cancer susceptibility

- www.jco.asopubs.org/cgi/content/abstract/21/12/2397? etoc

CancerGene

- www4.utsouthwestern.edu/breasthealth/cagene/

- UT Southwestern Medical Center at Dallas and the BayesMendel Group at Johns Hopkins free downloadable software for BRCA1, BRCA2, MLH1, MSH2 and MSH6 gene mutation probabilities, hypothetical pancreas gene mutation probability and age-specific breast, ovarian, colorectal, endometrial and pancreas cancer probabilities

GeneTests/GeneReviews

- www.geneclinics.org

- Information regarding genetic syndromes and available testing laboratories

Genetics home reference

- ghl.nlm.nih.gov

- Comprehensive guide to understanding genetic conditions

National Cancer Institute general cancer genetics information

- www.nci.nih.gov/cancerinfo/prevention-genetics-causes/ genetics

- Comprehensive guide to cancer genetics practice and commonly encountered syndromes

National Coalition for Health Professional Education in Genetics

- www.nshpeg.org

- Organization dedicated to providing education and access to information about advances in human genetics

National Comprehensive Cancer Network practice guidelines

- www.nccn.org/professionals/physician_gls

- The NCCN Clinical Practice Guidelines in Oncology ${ }^{\mathrm{TM}}$ are widely accepted policy guidelines for managing patients with inherited cancer susceptibility

National Organization of Rare Disorders

- www.rarediseases.org

- Provides comprehensive information on rare genetic conditions

Online Mendelian Inheritance in Man and Pubmed

- www.pubmed.com

- Online resource for locating journal articles and synopses of hereditary conditions

Standardized human pedigree nomenclature

- Bennet et al. [91]

important to elicit this information from the patient. High-risk lesions are also included for family members, such as atypical ductal hyperplasia, lobular carcinoma in situ, and any colon polyps and their pathology, if known. It is often helpful to obtain information on other physical findings that are observed in association with specific cancer syndromes.

For certain hereditary conditions, risk assessment models are available to assist in quantifying the probability that there is a heritable genetic mutation in the 
family. Risk models are available for both hereditary breast and ovarian cancer (HBOC) and hereditary nonpolyposis colon cancer (HNPCC) and have been in use for a number of years. These models take into account factors such as age of onset of cancer, number of affected relatives, presence or absence of associated cancers and ancestry (for HBOC) when calculating the likelihood of a mutation. Because there are multiple models available, with each model taking different factors into account, assessing accurately the probability of a gene mutation requires knowledge about the particular models that apply best to the characteristics of a particular patient and/ or family. Many patients tend to overestimate their risk for hereditary cancer [7], and therefore having an estimated probability is often helpful when making informed decisions about genetic testing. It is important to realize that risk assessment models have limitations, and in certain cases where there is limited family structure they may significantly over- or underestimate risk [8]. Therefore, risk assessment for hereditary cancer needs to reflect variables that current risk assessment models by themselves do not fully assess. This includes tumor pathology, limited family structure and presence of certain cancers in the family that may be part of a gene mutation spectrum but are not included in the model of risk calculation. Thus, risk assessment models, although helpful in guiding decisions about genetic testing, are tools that are not intended to be used in isolation and should not be used in place of clinical judgment [8]. The details regarding available risk assessment models are well covered in the National Cancer Institute website on cancer risk prediction (http://riskfactor.cancer.gov/cancer_ risk_prediction/).

There are several factors that can complicate both qualitative and quantitative risk assessment $[9,10]$. Hereditary cancer syndromes that involve a great deal of variable expression and/or decreased penetrance can be difficult to interpret in certain families. Also, with regard to sex-influenced and/or sex-limited cancers, risk assessment is complicated in families with a paucity of the susceptible sex. For any hereditary cancer syndrome, a small family size or a family in which there are barriers to communication creating incomplete or inaccurate information can make risk interpretation difficult. These barriers may include adoption, distancing among family members (geographical and/or psychosocial), limited availability of medical resources or lack of medical care, and families in which illnesses and cancer are not openly discussed, such as can be seen in certain cultures and religions $[9,11,12]$. Genetic professionals are trained at rec- ognizing these limitations and assessing risk in light of these challenges to provide an accurate assessment of the risk for a hereditary cancer syndrome.

\section{HBOC: A Model for Assessing Cancer Risk}

HBOC is one of the most common referrals to a cancer genetics center. It is estimated that around $7 \%$ of breast cancer cases and $10 \%$ of ovarian cancer cases have a hereditary cause $[13,14]$. The genes $B R C A 1$ and $B R C A 2$, which account for $84 \%$ of hereditary causes for breast and ovarian cancer, were cloned in 1994 and 1995, respectively [15-20]. Since their discovery, it has been recognized that these 2 genes are likely to account for a smaller portion of hereditary cases in the setting of isolated breast cancer in the absence of ovarian cancer. BRCA1, located at 17q21, and BRCA2, located at 13q12.3, both act as tumor suppressor genes on the cellular level, their protein products are part of the cellular response to DNA damage, and they are inherited in an autosomal dominant manner [16-20]. It is estimated that around $1 / 500$ to $1 / 1,000$ individuals in the general population carry a $B R C A 1$ mutation, while the exact prevalence of BRCA2 mutations in the general population is unknown [21]. Individuals who are Ashkenazi Jewish have a higher incidence of $B R C A 1$ and $B R C A 2$ gene mutations. Regardless of family history, it is estimated that $2.5 \%$ of Ashkenazi Jewish individuals carry a BRCA1 or BRCA2 mutation, with most (78-96\%) possessing 1 of the 3 founder mutations described as 185delAG and 5382incC on BRCA1 and 617delT on BRCA2 [22-29].

Due to the higher frequency of these 3 founder mutations in the Ashkenazi population, the testing strategy for these individuals is slightly different. In the USA, genetic testing for BRCA1 and BRCA2 is performed at Myriad Genetics Inc. [30]. This laboratory offers a Multisite 3 BRACAnalysis ${ }^{\circledR}$ to look specifically at the 3 founder mutations for Ashkenazi Jewish individuals. This test is less comprehensive and therefore less expensive, and averages a little over 400 USD. For those testing negative, or those who do not have an Ashkenazi Jewish background, this testing laboratory also offers comprehensive BRACAnalysis, which is estimated to detect mutations in over $88 \%$ of affected individuals with a mutation (unpublished data from Myriad Genetics) at a cost of a little over 3,000 USD [30]. In addition, this laboratory has recently introduced a new test referred to as BRACAnalysis Rearrangement Testing $(B A R T)^{\circledR}$, which has been discussed to detect mutations in $B R C A 1$ and $B R C A 2$ in a remaining 
$1-3 \%$ of affected individuals (unpublished data from Myriad Genetics) at a cost of 650 USD [30]. If a mutation is detected using any of these testing methods, family members then have the option of pursuing Single-Site BRACAnalysis for just under 400 USD to determine if they have inherited the mutation previously identified in a family member. Outside of the USA, other options for testing these 2 genes are available and, as with testing in the USA, techniques improve over time, leading to improved sensitivity. It is therefore stressed to the patients that it is important to periodically re-contact their counselor/physician to determine changes that may have occurred since testing was initiated.

Those who test positive for a $B R C A 1$ or $B R C A 2$ gene mutation are in a high-risk group to develop associated cancers. Cancer risks differ depending on which gene is found to carry a mutation. A review of the literature reveals discrepancies in the BRCA1- and BRCA2-associated cancer risks; however, the greatest risk for women is felt to be a risk for cancer of the breast, ovary, fallopian tube and peritoneum. While there is not a standard percentage risk quoted by all, most of the estimated lifetime risks quoted are similar. A study by King et al. [31] in 2003 estimated that the average risk of breast cancer for $B R C A 1$ or BRCA2 mutation carriers is $20 \%$ by the age of $40,55 \%$ by the age of 60 and $>80 \%$ by the age of 80 . These numbers indicate that the age of onset for breast cancer with $B R C A$ mutations is earlier than breast cancer in women in the general population, therefore making premenopausal breast cancer a red flag for identifying hereditary breast cancer families. In addition, while breast cancer is rare in the general population, it is much more common in those with $B R C A$ mutations. The average risk for ovarian cancer is felt to be higher with $B R C A 1$ mutations (cumulative risk of around 54\%) than with BRCA2 mutations (approx. risk of 23\%) [31].

Males with $B R C A$ mutations also carry an increased risk for certain types of cancers. Males with BRCA1 mutations are felt to be at a slightly increased risk for breast, prostate and pancreatic cancers; however, the risk for these cancers in BRCA2 mutation carriers is better defined. Males with BRCA2 mutations are felt to have a $6.9 \%$ risk for breast cancer before the age of 80 and a $20 \%$ risk for prostate cancer before the age of 80 , although the risk for prostate cancer is felt to be highest in males under 65 years of age [32-34]. Both men and women have an increased risk for pancreatic cancer, with the exact rate only differing slightly (3.2\% for men and $2.3 \%$ for women), and the risk in both sexes is greatest for those under 65 years of age $[33,34]$. Men and women with BRCA2 mutations have also been reported to have a slightly increased risk for cancers of the stomach, gallbladder and bile ducts, malignant melanoma (cutaneous and ocular), and those of the buccal cavity and pharynx, although the risk for these 4 cancers have not been consistent between studies $[33,34]$.

There are trends seen with mutations in these 2 genes as well. The majority of individuals with a family history of breast and ovarian cancer are found to have mutations in BRCA1. Breast cancers associated with germ line mutations in this gene are more often 'triple negative' for estrogen and progesterone receptor status as well as for HER-2 neu [35, 36]. In addition, ovarian cancers associated with $B R C A 1$ germ line mutations in particular are more likely to be papillary serous adenocarcinomas that are higher grade as compared to sporadic tumors and are less likely to be mucinous tumors [37]. Risks for contralateral breast cancer, following an initial diagnosis, differ between $B R C A 1$ and $B R C A 2$ women as well, with $B R C A 1$ mutation carriers showing a 5 -year risk of $27.1 \%$ and a 10 year risk of $43.4 \%$ while $B R C A 2$ mutation carriers display a 5 -year risk of $23.5 \%$ and a 10 -year risk of $34.6 \%$ [38]. In addition, it is felt that there is an ovarian cancer cluster region on the BRCA2 gene in exon 11 (nucleotides 30594075 at the $5^{\prime}$ boundary and 6503-6629 at the 3' boundary), where mutations are thought to be associated with a higher risk for developing ovarian cancer and a lower risk for developing breast cancer than for mutations found outside of this region [32, 33, 39]. Males with mutations falling within the ovarian cancer cluster region are also felt to have a $48 \%$ lower risk for developing prostate cancer by the age of 80 than males with mutations in other areas of the BRCA2 gene [32, 33].

\section{Identifying Families at Risk for a $B R C A 1$ or $B R C A 2$ Mutation}

The criteria for identifying families at risk for a hereditary cancer can be used in general or tailored to the gene/condition of suspicion. For example, pedigree analysis can be used to identify those suspected to be at an increased risk for a $B R C A 1$ or BRCA2 mutation by observing characteristics of an individual's personal and family history using the information known about associated cancer risks. In general, breast cancer occurring before the menopause (generally defined as under the age of 50), ovarian cancer, 2 or more primary breast cancers in the same individual, breast and ovarian cancer in the same individual, 2 or more individuals in the family with 
breast cancer and/or ovarian cancer, male breast cancer and Ashkenazi Jewish ancestry are factors that will increase one's risk for carrying a BRCA1 or BRCA2 gene mutation [10]. While this type of qualitative risk assessment is helpful, patients are often interested in a more quantitative estimate of their risk to test positive for a $B R C A$ mutation. A number of risk assessment models have been developed and are summarized well by Trepanier et al. [9]. These models differ in the number of affected individuals included, whether age of onset is included, whether bilateral breast cancer and/or ovarian cancer is included, whether Ashkenazi Jewish ancestry is included, whether the proband must be affected with breast cancer, and whether unaffected relatives or male breast cancer is taken into account. Therefore, it is important to elicit these details when obtaining the patient's medical and family history. It should also be kept in mind that each of these models has its limitations and therefore risk models should never be used alone but combined with qualitative assessment by a trained medical professional, such as a genetic counselor.

There is one popular computer program, called CancerGene, that was developed at UT Southwestern Medical Center, in conjunction with the Bayes-Mendel group at Johns Hopkins University, that allows the user to create a pedigree with first- and second-degree relatives of a proband and analyze this family history using several models to calculate the risk for a BRCA1 mutation, a $B R C A 2$ mutation or a combined risk for a mutation in either gene. The risk models used in this software include the Couch, Shattuck-Eidens, BRCAPRO and Myriad models. These risks are then displayed in a table format that allows for easy comparison. This program is available for health care professionals to download for free from the UT Southwestern Medical Center website; however, this program is not universally used by all centers and is far less frequently used in Europe [40]. In addition to providing a risk for a $B R C A$ mutation, there are 2 risk models available that will calculate the risk for developing breast cancer in an unaffected proband. These models are called Gail and Claus, and are available through this statistical software as well. Since the Gail model also incorporates personal medical information such as age at menarche, current age, age at first live birth, number of breast biopsies and whether or not these showed atypical hyperplasia and race of the proband, it is important to elicit these details either by an intake questionnaire or during the patient's appointment.

\section{Referring for Genetic Counseling: Why Is It Important and What Happens during a Genetic Counseling Session?}

Genetic counseling is vital and integral to the process of cancer risk assessment [41, 42]. It involves educating patients about their risk to develop cancer as well as the risk for hereditary cancer in the family, in order to assist them in gaining personal meaning from cancer genetic information and empowering them to make educated and informed decisions with regard to genetic testing and medical management planning. The first step to this process involves accurate medical and family history intake, which can be obtained both prior to and during the initial genetic counseling session. Many programs use a questionnaire or intake form that is completed by the patient and returned prior to the session in order to make the initial visit proceed efficiently. Important information to obtain during the intake process has been outlined earlier in this article under the 'cancer risk assessment' section and has also been extensively reviewed by Trepanier et al. [9] in 2004 and Berliner and Fay [10] in 2007.

There are several components to the genetic counseling session. In general, the session is initiated by filling in details of the family and medical history. Once these details have been clarified, the initial genetic counseling session allows the genetic professional time to educate the patient about sporadic, familial and hereditary cancer risks, basic genetics concepts and inheritance. In addition, the counselor uses this time to provide qualitative and, when appropriate, quantitative risk assessment to build a testing strategy, discuss potential test results and review the impact these results will have on medical and psychosocial management. The components of this initial session do not necessarily follow a fixed order but are a more fluid process that attempts to address each of these points while allowing the patient to dictate the order in which information is presented based on concerns raised and, to some extent, prior knowledge of genetic concepts and educational level. Here the components of the initial genetic counseling session are detailed to provide an understanding of the complexities of counseling these patients and the impact results can have on medical management.

\section{Medical History/Intake and Risk Assessment}

Obtaining basic family and medical history information prior to the session allows the genetics professional ample time to prepare for the initial counseling session. During this session it is important for the genetics profes- 
sional to first review medical and family history information. As discussed in previous sections, attention is paid to obtaining specific information regarding cancer diagnosed in the family. When reviewing a personal medical and family history with an individual or family who is at risk for $\mathrm{HBOC}$, there are some unique issues that need to be taken into consideration. Penetrance can be a complicating factor, since the lifetime risk for females to develop breast and/or ovarian cancer with HBOC is not $100 \%$. Some families harboring a $B R C A 1$ or $B R C A 2$ mutation may therefore have several unaffected relatives, especially in families where there is a disproportionate number of male relatives or in smaller-sized families. Indeed, there is an increased risk for both gender-limited cancer (ovarian) and gender-influenced cancer (breast) with HBOC, and families with several males and very few females may create difficulty in interpreting the risk for this condition. BRCA mutations (particularly BRCA2 mutations) involve an increased risk for cancers other than breast and ovary, albeit to a lesser degree. Thus, it should be taken into consideration that the presentation of these families may be nonclassic in some circumstances, such as having several cases of prostate cancer, pancreatic cancer and/or melanoma. Prior prophylactic surgeries of a cancer-susceptible organ in family members at risk for hereditary cancer can additionally make risk interpretation difficult. As an example, one or more females may have undergone early oophorectomy for reasons other than cancer treatment (such as secondary to complications with ovarian cysts).

Medical records, especially pathology reports, can be important when assessing hereditary cancer susceptibility. There are certain types of tumors that are more likely to be associated with specific genetic conditions. For this reason it is important whenever possible to confirm suspected diagnoses in the family with medical records. For example, individuals with lobular carcinoma in situ breast cancer are at a lower risk for BRCA mutations compared to individuals diagnosed as having invasive ductal breast cancer, since lobular carcinoma in situ is not considered to be part of the BRCA phenotype.

One of the reasons why obtaining records is so important is inaccuracy that exists in self-reporting cancers in the family. Several studies have evaluated the accuracy of self-reported cancers for family members and have suggested that breast cancer diagnoses tend to be reported accurately more often than ovarian cancers [43-46]. Even in those cases where breast cancer has been reported, records can help clarify if this cancer was invasive, in situ or atypical hyperplasia, since these specifics will affect the risk for a $B R C A$ mutation. In relatives with reported cases of 'female' cancer, or with otherwise unspecified abdominal cancers, it may be of use to pursue medical records to clarify these diagnoses and ultimately to provide a more accurate risk assessment. Likewise for those with colon, thyroid or other cancers, accurate reporting of pathology can significantly impact on the conditions to consider in the differential diagnosis. Since new information is discovered or may change with time, it is essential to encourage patients to report these changes so that the risk for hereditary cancer may be more accurately defined.

After obtaining and clarifying the necessary personal and family history, the session will often focus on educational aspects of genetic counseling, including a discussion of the differences between familial, sporadic and hereditary cancer. The patient is also counseled about general cancer genetics, chromosomes and inheritance aspects of hereditary cancer. For HBOC and most other hereditary cancer syndromes, inheritance is autosomal dominant. Thus, the patient is made aware that identifying the presence of a cancer-causing mutation will have implications for their immediate and extended family members. The patient is also informed about the cancer risks associated with the particular hereditary cancer syndrome being considered based on the family history, as well as various interventions available with regard to cancer risk reduction if a mutation were to be identified. Qualitative and quantitative risk assessment information is then discussed with the patient at length. The genetic counselor will review with the patient specific aspects of his/her personal and family history that would influence the likelihood of a cancer-causing mutation in the family, and also go over any available risk model calculations. For HBOC, this includes reviewing their risk for a $B R C A 1$ or BRCA2 mutation based on calculations from the CancerGene program with a concentration on the model(s) that provide the most accurate risk estimate based on variables specific to the patient's family history. Any complicating aspects of family history are pointed out to the patients so that they may understand any limitations to these risk numbers and to risk interpretation in general. If patients have a family history of breast cancer, the counselor will often also review with them their personal risk to develop breast cancer based on the Claus and Gail models, again making note of any potential limitations. For example, these models may underestimate the risks of developing breast cancer in families with characteristics suspicious for hereditary cancer. 
Table 4. Other major cancer syndromes associated with increased risk for breast cancer

\begin{tabular}{|c|c|c|c|}
\hline $\begin{array}{l}\text { Hereditary cancer } \\
\text { syndrome }\end{array}$ & $\begin{array}{l}\text { Associated } \\
\text { gene }\end{array}$ & General phenotype & $\begin{array}{l}\text { Testing de- } \\
\text { tection rate }\end{array}$ \\
\hline $\begin{array}{l}\text { Cowden } \\
\text { syndrome }\end{array}$ & PTEN & $\begin{array}{l}\text { Increased risk for multiple hamartomatous tumors, benign and malignant tumors } \\
\text { of the breast, thyroid and endometrium, and other physical manifestations such } \\
\text { as characteristic mucocutaneous skin lesions, macrocephaly and learning delays/ } \\
\text { mental retardation }\end{array}$ & $80 \%$ \\
\hline $\begin{array}{l}\text { Peutz-Jeghers } \\
\text { syndrome }\end{array}$ & STK11 & $\begin{array}{l}\text { Development of multiple hamartomatous gastrointestinal polyps, mucocutaneous } \\
\text { hyperpigmentation and increased risk for gastrointestinal cancer, breast cancer and } \\
\text { ovarian sex cord tumors in females and testicular tumors in males }\end{array}$ & $70 \%$ \\
\hline
\end{tabular}

During this risk assessment part of the session, it is important when analyzing the family history to consider any potential differential diagnoses. There are a number of hereditary cancer syndromes described other than HBOC that involve an increased risk for breast and/or ovarian cancer. The major characterized conditions that are associated with an increased risk for breast cancer include Cowden syndrome, Li-Fraumeni syndrome and PeutzJeghers syndrome. Table 4 gives a general overview of these conditions. Those individuals who carry a mutation in a mismatch repair gene associated with HNPCC (most often $M L H 1$ and $M S H 2$ mutations) have an increased risk for developing ovarian cancer. A more comprehensive review of these syndromes is beyond the scope of this paper, and there are many excellent reviews that have been previously published and are available through the National Cancer Institute (http://www.cancer.gov/) and the GeneTests website (http://www.geneclinics.org/). If the family history is suspicious for any of these differential conditions, this is brought up to the patient during the session including any available genetic testing for these conditions.

\section{Informed Consent and Other Legal/Ethical Issues}

Following a discussion of hereditary cancer and personalized risk assessment, if a patient elects to go forward with genetic testing, informed consent must be addressed prior to a blood draw. Informed consent involves a discussion of the genetic testing process, methodology and any potential risks involved with genetic testing. These implications are reviewed below and have also been discussed at length in previous review papers $[9,10]$. The different elements of informed consent have been outlined in more extensive detail by the American Society of Clinical Oncology in 1996. The vital components to informed consent include understanding the limitations, benefits and risks of molecular genetic testing, and general information about the technical aspects of genetic testing including detection rate, sensitivity and specificity of testing. Any limitations to test interpretation are reviewed with the patient. Patients are also made aware of the financial policy of the laboratory involved with genetic testing. This includes any potential monetary costs involved with testing and health insurance coverage. They should understand the alternatives to genetic testing, including the availability of DNA banking, and they should also be informed of laboratory policy for potential storage and/or reuse of genetic material.

There are a variety of other legal and ethical complications that may arise during the process of informed consent. Confidentiality issues should be addressed and include a discussion of when and how results will be disclosed to a patient, and if test information will be provided to his/her insurer, referring physician(s) and other medical professionals, and to any family members. Physicians should be aware of the potential ethical dilemmas that may arise with confidentiality, especially for cases where more than one family member may be seen by the same clinic, particularly when communication 
may not be open among those family members. Issues of confidentiality may extend also to individuals who are concerned about potential risks for genetic discrimination. This is a concern expressed by many patients and often influences their decision to go forward with genetic testing and even with the genetic counseling session itself. There are very few documented reports of genetic discrimination, and the actual risk to the patient is likely to be very low [47-49]. Currently in the USA there is both federal legislation, which includes the Health Insurance Portability and Accountability Act of 1996, and state legislation that has been enacted to restrict insurance company access to and use of genetic information [48]. Information regarding insurance discrimination, current federal and state-specific legislation, and laws that are currently in the process of being enacted (such as the Genetic Information Nondiscrimination Act or GINA of 2007) can be accessed through several websites, including http://thomas.loc.gov, http://www.ncsl.org and http:// www.genome.gov/PolicyEthics/. Despite current legislation, there are still gaps in this protection, and patients should be made aware of any potential risks and confidentiality about genetic information should be accordingly addressed. Patients should also be informed of life and disability insurance and employment discrimination, which are considered to be separate from health insurance. There is protection in place over employment discrimination through the Americans with Disabilities Act of 1995, which prohibits workplace discrimination of persons based on genetic tests and was issued by the Equal Employment Opportunity Commission [50].

The process of genetic testing and informed consent is founded on the principles of beneficence and nonmaleficence, which embody the goal that testing should not cause emotional or other harms to the patient or family members. This includes minors (those individuals under the age of 18) as well as patients who are under significant levels of psychological distress, who may not be able to appropriately cope with the process and/or outcome of genetic testing for hereditary cancer [51, 52]. Genetic testing for many hereditary cancer syndromes, including HBOC, is not typically offered to minors. The reasoning behind this consensus is partly that the test results will not have immediate implications with regard to cancer screening and surveillance for such conditions where the risk of developing cancer does not increase until adulthood. An exception exists for certain hereditary cancer syndromes that include a risk for childhood-onset tumors or cancer, such as Li-Fraumeni syndrome, familial adenomatous polyposis and multiple endocrine neopla- sias where medical intervention starts at a young age [ $[53$, 54]. There are other reasons to delay genetic testing of minors for adult-onset hereditary cancer syndromes. Testing a child for cancer susceptibility in the setting of HBOC may place them at a higher risk for potential future genetic discrimination. It is also viewed as removing choice, or violating the autonomy of the patient. Moreover, test results may adversely interfere in the parentchild attachment relationship, leading to overprotection of identified mutation carriers and lower self-esteem of children with unfavorable test results. This is based on the premise that most minors are unable to make fully independent and informed choices with regard to genetic testing and health care [53-55].

\section{Psychosocial Risk Assessment}

Patients will often face challenges during a counseling session with regard to genetic testing decision making and other issues, including communication with other family members, the potential risk for genetic discrimination, concerns for the well-being of other family members and constructing a personalized plan for cancer risk reduction via screening and management strategies. It is therefore important to elicit information from a patient regarding his/her expectations for the session, prior to having an in-depth discussion of the different aspects of hereditary cancer and genetic testing [9]. Assessing the motivations behind seeking out and using cancer genetics information is necessary in order to appreciate the different factors that influence a patient's risk perception for cancer development and/or hereditary cancer. This information can assist a health care professional in recognizing and understanding the potential impact of genetic test results on patient health care, quality of life and family and life planning decisions $[9,10,56-58]$.

Despite the ability to provide specific risk numbers for a particular gene mutation using risk models and family history, risk perception often remains largely based on emotional and psychosocial factors that have been shaped by a patient's experiences with cancer. It is these past experiences that may ultimately drive behaviors such as seeking genetic counseling and testing, their frequency and magnitude of cancer screening, and the decision of whether to pursue prophylactic surgery or other major preventative measures [10,59-61]. Appreciating psychosocial factors, such as personal coping strategies, current emotional state as well as various patient reactions and responses throughout the counseling session, can all assist in gauging risk perception and discussing cancer risk information in a way that is most helpful to a given patient. 


\section{Test Results and Implications for Health Care Management}

While the initial genetic counseling session focuses on establishing a testing strategy, when the patient elects to go forward with genetic testing, a posttest session is helpful in clarifying the importance of the result and implications this has for the individual and his/her family.

\section{Positive Test Result}

For those individuals with a confirmed mutation in a cancer susceptibility gene there are 3 main categories of available risk reduction and treatment options: surveillance, chemoprevention and prophylactic surgery. These options vary depending on the diagnosis, and not all are available for some of the rarer hereditary cancers. For the most common conditions, these options have created a whole group of individuals who were first termed 'cancer pre-vivors' by the support group Facing Our Risk of Cancer Empowered [62]. Cancer pre-vivors are individuals who carry a hereditary mutation, a family history of cancer or other predisposing factor but who have not been affected with cancer [62]. These individuals greatly benefit from the full range of options available to detect cancer at its earliest and most treatable stages or from chemoprevention and prophylactic surgical options that greatly reduce the overall risk for developing associated cancers. For example, those testing positive for a BRCA1 or BRCA2 mutation have the option of beginning screening at an earlier age (25-35 vs. 35-40 years in the general population) with breast self-examination, annual or semi-annual clinical examination and annual breast mammography and breast MRI (option of alternating between imaging techniques every 6 months), using tamoxifen as a chemoprevention option to lower the risk of developing breast cancer or electing prophylactic bilateral mastectomy to reduce the risk to develop this cancer by approximately 90\% [63-66]. In addition, these individuals also have options available to survey for ovarian cancer with CA-125 blood testing and transvaginal ultrasound, using oral contraceptives to decrease the risk of ovarian cancer or electing prophylactic oophorectomy (including fallopian tube removal) to decrease the risk of ovarian cancer by approximately $95 \%$ and reduce the risk of developing breast cancer in premenopausal individuals by $50 \%[63,64,67]$. These same options are of course available even to individuals who have already had a personal history of a BRCA-associated cancer, and in fact mutation status often affects surgical options for these individuals. In addition, genetic testing is also most in- formative if it is initiated in an individual with a personal history of a cancer associated with the condition of interest. Once a positive mutation has been found for this individual, testing becomes an informative option for anyone else in the family who is interested in learning their mutation status. Testing can then be used to identify those in the family who are also in a high-risk group for developing cancer, therefore benefiting from available management options, and those who have not inherited the predisposition in the family and should instead follow general population screening guidelines to manage their cancer risks. It is for this reason that mutation-positive individuals are counseled that they must inform their family members of their mutation status. Privacy laws prevent the counselor or medical professional from disclosing these results to family members without authorization from the patient [68].

Once a mutation has been identified in the family, it also opens the door to assisted reproductive technoloy (ART) options such as preimplantation genetic diagnosis (PGD), chorionic villus sampling and amniocentesis. While PGD allows the parents to select for fertilized eggs without a familial mutation to be implanted, prenatal testing options (chorionic villus sampling and amniocentesis) allow for genetic diagnosis during the pregnancy with the option of termination if the pregnancy is found to be affected. PGD was originally intended to help prevent pregnancies affected with high-penetrance lifethreatening genetic diseases [69]. These options are therefore controversial for conditions with reduced penetrance, especially when these conditions result in a risk for cancer that does not typically occur until after the age of 40 and especially given the effectiveness of current approaches in allowing for increased survival rates even once a cancer is detected $[70,71]$.

Use of PGD for BRCA1 or BRCA2 mutations has therefore been debated. In May 2006, the UK Human Fertilization and Embryology Authority agreed to allow PGD for the $B R C A$ genes, but there are no professional guidelines in the USA that have addressed the issue of guiding reproductive choice with cancer genetics tests $[69,72,73]$. While research has shown that some individuals will choose not to have children due to the fear of transmitting disease risk to the next generation, there are many factors to consider when determining the appropriateness of ART $[72,74]$. Some argue that if ART is not restricted to severe life-threatening conditions it will initiate a 'slippery slope', whereby the line between when to offer and not offer ART becomes less defined [72]. This could then open the door to ART for adult-onset condi- 
tions such as Parkinson or Alzheimer disease, multifactorial disorders such as mental illness or even some day allowing for individuals to use this technology to select for desirable traits for their children (i.e. musical ability or athleticism) [72]. In addition, there is a medical and psychological burden of this technology for the patient as well, since there are low odds for a successful pregnancy with PGD ( $<30 \%$ even after multiple attempts), and for women with hormone-sensitive cancers the process of PGD can increase the risk for development of these cancers [72].

\section{Negative Test Result}

Negative test results need to be interpreted within the context of the family history and with attention paid to whether the most informative member of the family was the individual initiating the testing process. Genetic testing should, whenever possible, be initiated in an individual with a personal history of a cancer associated with the condition of interest. If genetic testing is negative, and an unaffected individual was tested, the genetic counselor will always recommend proceeding with testing an affected family member for better interpretation of the test results. Until an affected family member is tested, a negative result is considered uninformative for several reasons: it is possible that a mutation in the gene tested exists in the family and it was not passed to the unaffected individual tested, it is possible that the family has a mutation in the gene tested that was not detectable with current technology, and it is also possible that the family carries a mutation in a different gene, perhaps even one that has not yet been discovered [9]. This is very difficult to sort out for a family when an uninformative family member has initiated the testing process.

Unfortunately, there is not always a living affected family member who can undergo genetic testing. In some instances testing options exist for the tumor tissue of a deceased individual or on DNA that is available if the individual banked his/her DNA prior to death. In other instances however, the only available option is to test an unaffected family member, making it necessary to use information about the family history of cancer to dictate an appropriate management strategy for those testing negative. For example, if an unaffected individual has a negative test result for $B R C A 1$ and $B R C A 2$ mutations, and has a strong family history of early-onset breast cancer and/or ovarian cancer, this individual would still be considered at an increased risk to develop these cancers and should be managed accordingly. When the family history is very suspicious for hereditary cancer, even if an affected fam-

Cancer Risk Assessment and Genetic

Counseling ily member were tested and found to be negative, it would still be considered appropriate to manage family members as if they are at a high risk to develop the cancers observed in the family, due to the possibility of an undetected mutation or other gene involvement. In this instance it would also be appropriate to explore research testing opportunities once available clinic testing options have been exhausted. Therefore, in light of a negative test result it is important to interpret this result within the context of the family history, relying on the methods of both quantitative and qualitative risk assessment to determine appropriate guidelines for managing the family's cancer risk.

When there is a known mutation in a cancer susceptibility gene identified in a close biologic family member and this is used to test others in the family, a negative test result is interpreted differently. In this instance the hereditary cause for cancer has been determined and those testing negative did not inherit this risk. Therefore, in most instances these individuals are considered to be at a general population risk to develop cancer. However, this would not hold true if they have a strong family history of cancer or have an ethnic background that puts them at high risk on the side of their family that has not yet undergone genetic testing. This is why it is important to gather the family history on both sides of the patient's family, even when they are coming in for testing of a known mutation [9]. The only additional exception to this rule that has been raised recently was discussed in a study [75] which suggested that the risk of breast cancer for $B R C A 1$ or $B R C A 2$ mutation families is influenced not only by the mutation itself but also by modifier genes. These authors demonstrated that individuals testing negative for a known mutation in the family are not at a general population risk to develop breast cancer but instead had an elevated risk based on inheritance of genetic modifiers [75]. These data have however not been reproduced and are questioned by some to be the result of ascertainment bias, suggesting that additional larger studies need to be conducted to investigate this further before any conclusions can be reached [76].

\section{Variant Test Result}

There is always a risk of finding a genetic variant of uncertain significance when undergoing genetic testing. A variant refers to a gene mutation that was identified but the effect on gene function and clinical significance is unclear. This is a very difficult result for patients because of the uncertainty in what it means for them and their family members. It is typically recommended that the individual's parents as well as other affected individuals are 
tested to determine whether or not the variant tracks with cancer in the family. In addition, co-occurrence of a variant with a known pathogenic mutation on the same gene makes it more likely that the variant is of limited clinical significance [77]. Depending on the hereditary cancer syndrome there may be research opportunities available to the family to determine the functional significance of the variant. Combining biochemical, epidemiologic and clinical data can provide some additional information about the significance of the variant and may ultimately lead to its reclassification [77]. However, until the variant is determined to be of clinical significance, predictive testing should not be offered to other family members and medical management recommendations should be made based on family history and degree of suspicion of a hereditary explanation for the cancers observed $[9,77]$.

\section{Psychosocial Impact of Testing for Hereditary Cancer Susceptibility}

There are many factors to explore when considering the psychosocial impact that testing for inherited cancer susceptibility will have for a patient and their family. These include perception of risk prior to and after testing and for those who test positive the inability to predict when cancer will occur and how severe it may be if it does occur. In addition, for certain hereditary cancer syndromes, medical management guidelines may be unclear. Other psychosocial issues may include loss of confidentiality and autonomous decision making when involving the whole family in the testing process, as well as survivor's guilt for those testing negative in a family with a known mutation $[78,79]$. In addition, those who test positive for a genetic variant are left with an uncertain test result that is neither positive nor negative, and this can create distress for these individuals.

When addressing the psychosocial impact of genetic testing, it is important to keep in mind that a result will elicit a different reaction, and have unique meaning, for each person undergoing testing, since the significance of this result will be influenced by the patient's own life experiences, culture, values and personality traits [78]. The initial counseling session is an important time to assess the meaning a positive, negative or variant test result will have for the patient. The initial session also gives the counselor time to assess the patient's perception of their risk to develop cancer. Patients receiving counseling for $B R C A 1$ and $B R C A 2$ for example have been found to overestimate their risks for breast cancer and their risk to test positive with genetic testing [80]. The initial counseling session therefore allows time to address these concerns and discuss the true risk for a hereditary mutation based on qualitative and quantitative assessment of the family history. It also allows time for the counselor to explore the patient's motivation for testing. These motivations typically center on the need to better understand one's cancer risks, the desire to provide this information for children and immediate/extended relatives, the desire to use this information to make informed decisions regarding medical management, and the ability to use this information to make reproductive decisions [80]. Due to the motivations for genetic testing, the initial session also allows the counselor to learn more about the family dynamic so that barriers to communicating these results to the immediate and extended family can be explored.

For patients pursuing genetic testing, the initial counseling session should be followed with close assessment of the patient reaction to the result during a posttest counseling session. Some patients may find their results reassuring, motivating and even empowering, while others may be anxious, frightened, depressed and feel a sense of doom by the same result [78]. The latter group of individuals is especially at risk to have a negative self-concept after genetic testing, believing themselves to be unwell even if they were healthy prior to undergoing testing [78]. As with during the initial counseling session, it is important to keep in mind that the reaction to one's genetic test result is influenced not only by an individual's personal experiences with cancer, but also by many other facets to his/her personality, values and culture. In addition to the reaction an individual has toward this result, if a positive test result has been identified, the patient is also advised to share these results with the immediate and extended family members. The genetic counselor assists in this process, suggesting who in the family would be best to test in order to determine from which side of the family a mutation originated. Once this is determined the counselor provides tools, such as a form letter, which allows the patient to easily inform the immediate and extended family members of their risk for hereditary cancer and available testing and counseling in their area. This type of information sharing may result in internal family conflicts and tension. For those electing testing, it is difficult to understand the motivations for someone to forgo testing, and likewise for individuals who elect not to proceed with genetic testing it may be difficult to understand why a family member would be interested in understanding if they are at high risk to develop cancer. Genetic testing is not right for everyone, and individualized counseling is essential in establishing a support network, as well as de- 
termining the appropriateness of testing for the individual.

Even with the psychosocial concerns raised regarding the testing process, when talking with patients some studies have shown that patients were actually not as worried about potential negative effects of testing, such as insurance discrimination and confidentiality, as they were motivated by the positive effects that may result from the testing process $[81,82]$. In addition, research has shown that patients are overall satisfied with the process of genetic counseling for inherited cancer susceptibility $[81,83,84]$. One reason for this satisfaction may be inherent to the genetic counseling process, since it has been shown that patients are typically more satisfied with medical care when the information is tailored to their coping style [83-85]. Genetic counselors are specially equipped for this process due to the training they receive in both the psychosocial aspects that arise when counseling individuals and providing an educational component to the session that allows for informed decision making.

\section{Future Directions: New Genetic Testing and Uncovering the Genetic Components behind 'Familial' Breast Cancer}

With the ongoing efforts and success of projects such as the International HapMap project, there has been continued refinement of genetic testing for more common human diseases, including cancer. Additionally, as more is being understood regarding human genetic variation, new clinical genetic tests for these variants are likely to be developed. The interpretation of these tests may be complicated with respect to a patient's health care. For families with multiple cases of breast cancer and negative $B R C A$ analysis, the cancer in the family is likely to be explained by a combination of factors, including low-penetrance genes that moderately increase the risk of developing breast cancer in addition to environmental factors. One such example is the $1100 \mathrm{delC}$ mutation in the CHEK2 gene, which has been shown to increase the risk of developing breast cancer by approximately 2-fold [86, 87]. The implications of carrying this single variation alone are likely to be small, especially in comparison to $B R C A$ mutations. Thus, being found to carry the $1100 \mathrm{delC}$ CHEK2 variant, or not to carry it, has in itself little impact on screening and management for breast cancer. However, as more of these variations are uncovered, each harboring its own risk for breast cancer, it is not unreasonable to think that future genetic testing may involve panels of tests for a number of susceptibility variants, ultimately producing a personalized risk 'profile' for breast cancer. In the past year or two alone, several articles have been published on multiple genetic variants that increase susceptibility to breast cancer [88-90]. As genetic testing and its interpretation evolve and become further integrated into health care, it will become increasingly important for health care professionals to be familiar with the genetic testing and counseling process, and to recognize the need for referring a patient to genetics.

\section{Putting It All Together: Applying Cancer Genetics Concepts to Clinical Practice}

As this article has demonstrated, it is important to identify individuals at risk for hereditary cancer susceptibility giving the opportunity to guide appropriate medical management. Genetic counselors have unique training that enables them to provide qualitative and quantitative risk assessment to guide patients through the testing process in a supportive environment where attention is paid to the psychosocial impact of these results and the complexity of their interpretation. It is therefore helpful for medical professionals to have tools which allow for identifying appropriate referrals.

There are several tools provided here which can enable the medical professional to easily identify appropriate referrals and streamline the process of identifying these individuals with limited modifications to their current practice. As provided in table 1, there are 'red flags' of a patient's personal medical history and family history which aid in identifying those at an increased risk for a hereditary cancer syndrome. These red flags can be adapted for practice in several ways, such as a physician's pocket guide or patient intake questionnaire. Table 2 shows one example of how this information can be adapted to a physician's pocket guide to identify families at an increased risk for HBOC. This pocket guide can be customized to a clinical setting based on conditions that may be commonly encountered (i.e. HBOC in a high-risk breast health center, or HNPCC- and familial-adenomatous-polyposis-guided questions in a gastrointestinal practice) and can then accompany physicians, residents, nurses and other medical professionals working with patients to quickly identify appropriate referrals. Once these individuals have been identified, it helps to streamline the process of referring these patients to a trained genetics professional. Figure 1 provides a fax referral form, which includes key elements essential to communicating 


\section{Referral to Cancer Genetics Clinic}

[Option of adding genetics department contact information here: name, address, phone and fax numbers]

Please communicate the following information via fax, phone or mail. All of the fields must be filled in before an appointment can be made for your patient.

Referrer's name Referrer's phone

Contact person (individual filling out this form)

Referrer's address

Referrer's fax number Date

Patient's name Patient's phone

Patient's UAB MR No. (if applicable) Patient's date of birth

Patient's address

\section{Indications for referral (please check all that apply) \\ Early-age onset of cancer ( $<50$ years) \\ Bilateral or multiple primary cancer \\ Clustering of cancer in the same individual or close blood relatives on same side of family (breast/ovarian, breast/uterine and/or thyroid, colon/uterine, melanoma/pancreatic) \\ Rare cancers (male breast cancer, sarcoma, adrenocortical carcinoma, brain tumors) \\ Colon adenomas ( $<40$ years) \\ Multiple dermatologic manifestations with personal and/or family history of cancer (lipomas, fibromas, neurofibromas, dysplastic nevi, basal cell carcinoma, melanoma) \\ $\square \quad$ Member of a family with a known mutation in a cancer susceptibility gene (BRCA1/BRCA2, HNPCC-associated mutation or other mutation) \\ * The maternal and paternal sides of the family should be considered independently for familial patterns of cancer. \\ * Please call us if you are interested in receiving a 'risk assessment criteria' pocket physician's guide.}

Type(s) of cancer in the family history:

Fig. 1. Example of a fax referral form.

the aspects of the patient's medical and family history which have prompted a referral to a genetics professional for further evaluation. This process of information-driven referrals is essential to ensuring an open communication process between referral sources and the genetics center. Figure 1 is a guide listing essential resources used by most cancer genetics centers. This guide identifies appropriate online resources for increasing knowledge in the area of cancer genetics as well as common tools used by the cancer genetic counselor.
The aim of this paper was to introduce the medical professional to the components and complexities of cancer genetic counseling and, therefore, should serve as a guide to understanding this process. By use of the tools provided and information discussed, we hoped to make it easier for professionals to incorporate this information in their practice with the understanding of the impact gene testing can have on guiding medical management for patients. 


\section{Disclaimer}

This review presents and discusses the different aspects of cancer genetic counseling as conducted in the USA. Although several issues relevant to this subject are addressed here on a general level, it should be recognized that there may be cultural and geographical differences regarding the manner in which genetic counseling and testing for hereditary cancer is practiced in different centers and/or internationally. These differences will particularly impact on psychosocial aspects of the genetic counseling and testing process, as well as details involving informed consent and the financial aspects of genetic testing. Due to the limited length of this paper, not all of these cultural differences could be addressed in detail.

\section{References}

1 Vogelstein B, Kinzler KW: The multistep nature of cancer. Trends Genet 1993;9:138141.

2 Claus ER, Risch N, Thompson WD: Genetic analysis of breast cancer in the cancer and steroid hormone study. Am J Hum Genet 1991;48:232-242.

3 Willett W: Recent findings regarding lifestyle risk factors in the epidemiology of breast and colon cancer; in Fortner RJ (ed): Accomplishments in Cancer Research. Philadelphia, Lippincott, 1993, pp 164-178.

4 Chen PL, Sellers TA, Rich SS, Potter JD, Folsom AR: Examination of the effect of nongenetic risk factors on the familial risk of breast cancer among relatives of postmenopausal breast cancer patients. Cancer Epidemiol Biomarkers Prev 1994;3:549-555.

5 Kinsler KW, Vogelstein B: Lessons from hereditary colorectal cancer. Cell 1996;87:159170.

6 Hampel H, Sweet K, Westman JA, Offit K, Eng C: Referral for cancer genetics consultation: a review and compilation of risk assessment criteria. J Med Genet 2004;41:81-91.

-7 Burke W, Culver JO, Bowen D, Lowry D, Durfy S, McTiernan A, Anderson MR: Genetic counseling for women with an intermediate family history of breast cancer. Am J Med Genet 2000;90:361-368.

$\checkmark 8$ Weitzel JN, Lagos VI, Cullinane CA, Gambol PJ, Culver JO, Blazer KR, Palomares MR, Lowstuter KJ, MacDonald DJ: Limited family structure and BRCA gene mutation status in single cases of breast cancer. JAMA 2007; 297:2587-2595.

\9 Trepanier A, Ahrens M, McKinnon W, Peters J, Stopfer J, Grumet SC, Manley S, Culver JO, Acton R, Larsen-Haidle J, Correia LA, Bennett R, Pettersen B, Ferlita TD, Costalas JW, Hunt K, Donlon S, Skrzynia C, Farrell C, Callif-Daley F, Vockley CW: Genetic cancer risk assessment and counseling: recommendations of the national society of genetic counselors. J Genet Counsel 2004;13:83114.

10 Berliner JL, Fay AM: Risk assessment and genetic counseling for hereditary breast and ovarian cancer: recommendations of the national society of genetic counselors. J Genet Counsel 2007;16:241-260.
11 Lynch HT, Drouhard T, Vasen HF, Cavalieri J, Lynch J, Nord S, Smyrk T, Lanspa S, Murphy P, Whelan KL, Peters J, de la Chapelle A: Genetic counseling in a Navajo hereditary nonpolyposis colorectal cancer kindred. Cancer 1996;77:30-35.

12 Mitchell JL: Cross-cultural issues in the disclosure of cancer. Cancer Pract 1998;6:153160.

13 American Medical Association: Identifying and managing hereditary risk for breast and ovarian cancer, April 2001.

14 Claus EB, Risch N, Thompson WD: Autosomal dominant inheritance of early-onset breast cancer. Cancer 1994;73:643-651.

15 Ford D, Easton DF, Stratton M, Narod S, Goldgar D, Devilee P, Bishop DT, Weber B, Lenoir G, Chang-Claude J, Sobol H, Teare MD, Struewing J, Arason A, Scherneck S, Peto J, Rebbeck TR, Tonin P, Neuhausen S, Barkardottir R, Eyfjord J, Lynch H, Ponder BA, Gayther SA, Zelada-Hedman M; The Breast Cancer Linkage Consortium: genetic heterogeneity and penetrance analysis of the $B R C A 1$ and BRCA2 genes in breast cancer families. Am J Hum Genet 1998;62:676689.

16 Miki Y, Swensen J, Shattuck-Eidens D, Futreal PA, Harshman K, Tavtigian S, Liu Q, Cocharn C, Bennett LM, Ding W: A strong candidate for the breast and ovarian cancer susceptibility gene BRCA1. Science 1994; 266:66-71.

17 Hall JM, Lee MK, Newman B, Morrow JE, Anderson LA, Huey B, King MC: Linkage of early-onset familial breast cancer to chromosome 17q21. Science 1990;250:16841689.

18 Narod SA, Feunteum J, Lynch HT, Watson P, Conway T, Lynch J, Lenoir GM: Familial breast-ovarian cancer locus on chromosome 17q12-q23. Lancet 1991;338:82-83.

19 Wooster R, Bignell G, Lancaster J, Swift S, Seal S, Mangion J, Collins N, Gergory S, Gumbs C, Micklem G: Identification of the breast cancer susceptibility gene BRCA2. Nature 1995;378:789-791.

20 Wooster R, Neuhausen SL, Mangion J, Quirk Y, Ford D, Collins N, Nguyen K, Seal S, Tran T, Averill D: Localization of a breast-cancer susceptibility gene, BRCA2, to chromosome 13q12-13. Science 1994;265:2088-2090.
21 Szabo CI, King MC: Population genetics of BRCA1 and BRCA2. Am J Hum Genet 1997; 60:1013-1020.

22 Struewing JP, Beliovich D, Peretz T, Avishai N, Kaback MM, Collins FS, Brody LC: The carrier frequency of the BRCA1 185delAG mutation is approximately 1 percent in Ashkenazi Jewish individuals. Nat Genet 1995; 11:198-200.

23 Neuhausen S, Gilewski T, Norton L, Tran T, McGuire P, Swensen J, Hampel H, Borgen P, Brown K, Skolnick M, Shattuck-Eidens D, Jhanwar S, Goldgar D, Offit K: Recurrent BRCA2 6174delT mutations in Ashkenazi Jewish women affected by breast cancer. Nat Genet 1996;13:126-128.

-24 Levey-Lahad E, Catane R, Eisenberg S, Kaufman B, Hornreich G, Lishinsky E, Shohat M, Weber BL, Beller U, Lahad A, Halle D: Founder BRCA1 and BRCA2 mutations in Ashkenazi Jews in Israel: frequency and differential penetrance in ovarian cancer and in breast-ovarian cancer families. Am J Hum Genet 1997;60:1059-1067.

25 Couch FJ, Weber BL: Mutations and polymorphisms in the familial early-onset breast cancer (BRCA1) gene. Breast cancer information core. Hum Mutat 1996;8:8-18.

26 Roe BB, Boyd AA, Volcik K, Richards CS: Ashkenazi Jewish population frequencies for common mutations in BRCA1 and BRCA2. Nat Genet 1996;14:185-187.

27 Moslehi R, Chu W, Karlan B, Fishman D, Risch H, Fields A, Smotkin D, Ben-David Y, Rosenblatt J, Russo D, Schwartz P, Tung N, Warner E, Rosen B, Friedman J, Brunet JS, Narod SA: BRCA1 and BRCA2 mutation analysis of 208 Ashkenazi Jewish women with ovarian cancer. Am J Hum Genet 2000; 66:1259-1272.

28 Rubinstein WS: Hereditary breast cancer in Jews. Fam Cancer 2004;3:249-257.

29 Robles-Diaz L, Goldfrank DJ, Kauff ND, Robson M, Offit K: Hereditary ovarian cancer in Ashkenazi Jews. Fam Cancer 2004;3: 259-264.

30 Myriad Genetics Inc. 2007. www.myriad. com.

31 King MC, Markes JH, Mandell JB: Breast and ovarian cancer risks due to inherited mutations in BRCA1 and BRCA2. Science 2003. 303:643-646. 
-32 Thompson D, Easton D: Variation in cancer risks, by mutation position, in BRCA2 mutation carriers. Am J Hum Genet 2001;68:410419.

-33 Liede A, Karlan BY, Narod SA: Cancer risks for male carriers of germline mutations in $B R C A 1$ or BRCA2: a review of the literature. J Clin Oncol 2004;22:735-742.

-34 The Breast Cancer Linkage Consortium: Cancer risks in BRCA2 mutation carriers. J Natl Cancer Inst 1999;91:1310-1316.

- 35 Easton DF, Bishop DT, Ford D, Crockford GP, the Breast Cancer Linkage Consortium: Genetic linkage analysis in familial breast and ovarian cancer. Am J Hum Genet 1993; 52:678-701.

>36 Lakhani SR, Van de Vijver MJ, Jacquemier J, Anderson TJ, Osin PP, McGuffog L, Easton DF: The pathology of familial breast cancer: predictive value of immunohistochemical markers estrogen receptor, progesterone receptor, HER-2, and p53 in patients with mutations in BRCA1 and BRCA2. J Clin Oncol 2002;20:2310-2318.

>37 Lakhani SR, Manek S, Penault-Llorca F, Flanagan A, Arnout L, Merrett S, McGuffog L, Steele D, Devilee P, Klijn JG, Meijers-Heijboer H, Radice P, Pilotti S, Nevanlinna H, Butzow R, Sobol H, Jacquemier J, Lyonet DS, Neuhausen SL, Weber B, Wagner T, Winqvist R, Bignon YJ, Monti F, Schmitt F, Lenoir G, Seitz S, Hamman U, Pharoah P, Lane G, Ponder B, Bishop DT, Easton DF: Pathology of ovarian cancer in BRCA1 and BRCA2 carriers. Clin Cancer Res 2004; 10: 2473-2481.

$>38$ Metcalfe K, Lynch HT, Ghadirian P, Tung N, Olivotto I, Warner E, Olopade OI, Eisen A, Weber B, McLennan J, Sun P, Foulkes WD, Narod SA: Contralateral breast cancer in $B R C A 1$ and BRCA 2 mutation carriers. J Clin Oncol 2004;22:2328-2335.

>39 Gayther SA, Magion J, Russell P, Seal S, Barfoot R, Ponder BA, Stratton MR, Easton D: Variation of risks of breast and ovarian cancer associated with different germline mutations of the BRCA2 gene. Nat Genet 1997;15: 103-105.

40 UT Southwestern Medical Center at Dallas and the Bayes-Mendel Group at Johns Hopkins CancerGene with BRCAPRO, MMRpro, and PancPRO. 2007. http://www4.utsouthwestern.edu/breasthealth/cagene/.

41 Peters JA, Stopfer JE: Role of the genetic counselor in familial cancer. Oncology 1996 10:159-166.

-42 Stopfer JE: Genetic counseling and clinical cancer genetics services. Semin Surg Onc 2000;18:347-357.

43 Love RR, Evans AM, Josten DM: The accuracy of patient reports of a family history of cancer. J Chronic Dis 1985;38:289-293.

-44 Theis B, Boyd N, Lockwood G, Tritchler D: Accuracy of family cancer history in breast cancer patients. Eur J Cancer Prev 1994;3: 321-327.
45 Douglas FS, O’Dair LC, Robinson M, Evans DG, Lynch SA: The accuracy of diagnoses as reported in families with cancer: a retrospective study. J Med Genet 1999;36:309312.

46 Ziogas A, Anton-Culver H: Validation of family history data in cancer family registries. Am J Prev Med 2003;24:190-198.

47 Hall MA: Genetic discrimination: Fact sheet commissioned by the North Carolina Genomics and Bioinformatics Consortium, LLC, and adapted from materials written for the HEIRS study in conjunction with Jean McEwen at NIH. 2001. www.ncbiotech.org/.

48 Greely HT: Banning genetic discrimination. NEJM 2005;353:865-867.

49 Hall MA, Rich SS: Laws restricting health insurers' use of genetic information: impact on genetic discrimination. Am J Hum Genet 2000;66:293-307.

50 EEOC: Compliance Manual. 1995, vol 2, sect 902, order 915.002, pp 902-945.

-51 Lerman C, Lustbader E, Rimer, B, Daly M, Miller S, Sands C: Effects of individualized breast cancer risk counseling: a randomized trial. J Natl Can Inst 1995;87:286-292.

52 Audrain J, Schwartz MD, Lerman C, Hughes C, Peshkin BN, Biesecker B: Psychological distress in women seeking genetic counseling for breast-ovarian cancer risk: the contributions of personality and appraisal. Ann Behav Med 1998;19:370-377.

53 American Society of Clinical Oncology: Statement of the American Society of Clinical Oncology: genetic testing for cancer susceptibility. J Clin Oncol 1996;14:1730-1740.

54 American College of Medical Genetics Foundation: Genetic susceptibility to breast and ovarian cancer: assessment, counseling and testing guidelines. New York, American College of Medical Genetics Foundation, 1999.

55 MacDonald D, Lessick M: Hereditary cancers in children and ethical and psychosocial implications. J Pediatr Nurs 2000;15:217225.

56 Biesecker BB: Psychological issues in cancer genetics. Semin Oncol Nurs 1997;13:129134.

57 Croyle RT: Psychosocial aspects of cancer genetic testing: a research clinicians update. Cancer 1997;80:569-575.

58 Hopwood P: Psychological issues in cancer genetics: current research and future priorities. Patient Educ Counsel 1997;32:19-31.

59 Weil J: Psychosocial Genetic Counseling. New York, Oxford University Press, 2000.

60 Schneider K: Counseling about Cancer: Strategies for Genetic Counselors, ed 2. New York, Wiley-Liss, 2002.

61 Patenaude AF: Genetic Testing for Cancer: Psychological Approaches for Helping $\mathrm{Pa}$ tients and Families. Washington, American Psychological Association, 2005.

62 Facing Our Risk of Cancer Empowered (FORCE). Last updated July 2007. www. facingourrisk.net.
63 Narod SA, Offit K: Prevention and management of hereditary breast cancer. J Clin Oncol 2005;23:1656-1663.

64 Calderon-Margalit R, Paltiel O: Prevention of breast cancer in women who carry BRCA1 or BRCA2 mutations: a critical review of the literature. Int J Cancer 2004;112:357-364.

65 Rebbeck TR, Friebel T, Lynch HT, Neuhausen SL, van't Verr L, Garber JE, Evans GR, Narod SA, Isaacs C, Matloff E, Daly MB, Olopade OI, Weber BL: Bilateral prophylactic mastectomy reduces breast cancer risk in BRCA1 and BRCA2 mutation carriers: the PROSE study group. J Clin Oncol 2004;22: 1055-1062.

-66 Saslow D, Boetes C, Burke W, Harms S, Leach MO, Lehman CD, Morris E, Pisano E, Schnall M, Sener S, Smith RA, Warner E, Yaffe M, Andrews KS, Russell CA, American Cancer Society Breast Cancer Advisory Group: American Cancer Society guidelines for breast screening with MRI as an adjunct to mammography. CA Cancer J Clin 2007; 57:75-89.

-67 Finch A, Beiner M, Lubinski J, Lynch HT, Moller P, Rosen B, Murphy J, Ghadirian P, Friedman E, Foulkes WD, Kim-Sing C, Wagner T, Tung N, Couch F, Stoppa-Lyonnet D, Ainsworth P, Daly M, Pasini B, GershoniBaruch R, Eng C, Olopade OI, McLennan J, Karlan B, Weitzel J, Sun P, Narod SA, Hereditary Ovarian Cancer Clinical Study Group: Salpingo-oophorectomy and the risk of ovarian, fallopian tube, and peritoneal cancers in women with a BRCA1 or BRCA2 mutation. JAMA 2002;296:185-192.

68 United States Department of Health and Human Services. Last revised August 2007. www.hhs.gov/ocr/hipaa.

-69 Menon U, Harper J, Sharma A, Fraser L, Burnell M, Elmasry K, Rodeck C, Jacobs I: Views of BRCA gene mutation carriers on preimplantation genetic diagnosis as a reproductive option for hereditary breast and ovarian cancer. Hum Reprod 2007;22:1573-1577.

70 Spits C, De Ryche M, Van Ranst N, Verpoest W, Lissens W, Van Steirteghem A, Liebaers I, Sermon K: Preimplantation genetic diagnosis for cancer predisposition syndromes. Prenat Diagn 2007;27:447-456.

71 Offit K, Sagi M, Hurley K: Preimplantation genetic diagnosis for cancer syndromes: a new challenge for preventive medicine. JAMA 2006;296:2727-2730.

72 American Society of Clinical Oncology: American Society of Clinical Oncology policy statement update. J Clin Oncol 2003;21: 2397-2406

73 Smith KR, Ellington L, Chan AY, Croyle RT, Botkin JR: Fertility intentions following testing for a BRCA1 gene mutation. Cancer Epidemiol Biomarkers Prev 2004;13:733740

Prucka/McIlvried/Korf 
74 Smith A, Moran A, Boyd MC, Bulman M, Shenton A, Smith L, Iddenden R, Woodward ER, Lalloo F, Maher ER, Evans DG: Phenocopies in BRCA1 and BRCA2 families: evidence for modifier genes and implications for screening. J Med Genet 2007;44:10-15.

-75 Goldgar D, Venne V, Conner T, Buys S: BRCA phenocopies or ascertainment bias? J Med Genet 2007;44:e86.

76 Gomez-Garcia EB, Ambergen T, Block MJ, van den Wijngaard A: Patients with an unclassified variant in the $B R C A 1$ or $B R C A 2$ genes show different clinical features from those with a mutation. J Clin Oncol 2005;23: 2185-2190.

-77 Calzone KA, Biesecker BB: Genetic testing for cancer predisposition. Cancer Nurs 2002; 25:15-25.

-78 Claes E, Evers-Kiebooms G, Denayer L, Decruyenaere M, Boogaerts A, Philippe K, Legius E: Predictive genetic testing for hereditarybreast and ovarian cancer: psychological distress and illness representations 1 year following disclosure. J Genet Couns 2005; 14 : 349-363.

79 Pasacreta JV: Psychosocial issues associated with genetic testing for breast and ovarian cancer risk: an integrative review. Cancer Invest 2003;21:588-623.

80 Clark S, Bluman LG, Borstelmann N, Regan K, Winer EP, Rimer BK, Skinner CS: Patient motivation, satisfaction, and coping in genetic counseling and testing for $B R C A 1$ and BRCA2. J Genet Couns 2000;9:219-235.
81 Lerman C, Narod S, Schulman K, Hughes C, Gomez-Caminero A, Bonney G, Gold K, Trock B, Main D, Lynch J, Fulmore C, Snyder C, Lemon SJ, Conway T, Tonin P, Lenoir G, Lynch H: BRCA1 testing in families with hereditary breast-ovarian cancer: a prospective study of patient decision making and outcomes. JAMA 1996;275:1885-1892.

82 DeMarco TA, Peshkin BN, Mars BD, Tercyak KP: Patient satisfaction with cancer genetic counseling: a psychometric analysis of the genetic counseling satisfaction scale. J Genet Couns 2004;13:293-304.

83 Nordin K, Liden A, Hansson M, Rosenquist R, Berglund G: Coping style, psychological distress, risk perception, and satisfaction in subjects attending genetic counseling for hereditary cancer. J Med Genet 2002;39:689694.

84 Ludwick-Rosenthal R, Neufeld R: Preparation for undergoing an invasive medical procedure: interacting effects of information and coping style. J Consult Clin Psychol 1993;61:156-164.

85 Steptoe A, Sutcliffe I, Allen B, Combes C: Satisfaction with communication, medical knowledge, and coping style in patients with metastatic cancer. Soc Sci Med 1991;32:627632.

86 Vahteristo P, Bartkova J, Eerola H, Syrjakoski K, Ojala S, Kilpivaara O, Tamminen A, Kononen J, Aittomaki K, Heikkila P, Holli K, Blomqvist C, Bartek J, Kallioniemi OP, $\mathrm{Ne}$ vanlinna $\mathrm{H}$ : A CHEK2 genetic variant contributing to a substantial fraction of familial breast cancer. Am J Hum Genet 2002;71: 432-438.
87 The CHEK2 Breast Cancer Case-Control Consortium: CHEK2*1100delC and susceptibility to breast cancer: a collaborative analysis involving 10,860 breast cancer cases and 9,065 controls from 10 studies. Am J Hum Genet 2004;74:1175-1182.

88 Easton DF, Pooley KA, Dunning AM, Pharoah $\mathrm{PD}$, Thompson D, Ballinger DG, Struewing JP, Morrison J, Field H, Luben R, Wareham N, Ahmed S, Healey CS, Bowman R, SEARCH collaborators: Genome-wide association study identifies novel breast cancer susceptibility loci. Nature 2007;447:10871093.

89 Hunter DJ, Kraft P, Jacobs KB, Cox DG, Yeager M, Hankinson SE, Wacholder S, Wang Z, Welch R, Hutchinson A, Wang J, Yu K, Chatterjee N, Orr N, Willett WC, Colditz GA, Ziegler RG, Berg CD, Buys SS, McCarty CA, Feigelson HS, Calle EE, Thun MJ, Hayes RB, Tucker M, Gerhard DS, Fraumeni JF Jr, Hoover RN, Thomas G, Chanock SJ: A genome-wide association study identifies alleles in FGFR2 associated with risk of sporadic postmenopausal breast cancer. Nat Genet 2007;39:870-874.

90 Pharoah PD, Tyrer J, Dunning AM, Easton DF, Ponder BA. SEARCH investigators: Association between common variation in 120 candidate genes and breast cancer risk. PLoS Genet 2007;3:e42.

-91 Bennet RL, Steinhaus KA, Uhrich SB, O'Sullivan CK, Resta RG, Lockner-Doyle D, Markel DS, Vincent V, Hamanishi J: Recommendations for standardized human pedigree nomenclature. Am J Hum Genet 1995; 56:745-752. 